\title{
Cause-specific mortality of Dutch chlorophenoxy herbicide manufacturing workers
}

D Boers, L Portengen, H Bas Bueno-de-Mesquita, et al.

Occup Environ Med 2010 67: 24-31 originally published online September 6, 2009

doi: 10.1136/oem.2008.044222

Updated information and services can be found at:

http://oem.bmj.com/content/67/1/24.full.html

\section{These include:}

References This article cites 25 articles, 9 of which can be accessed free at: http://oem.bmj.com/content/67/1/24.full.html\#ref-list-1

Email alerting Receive free email alerts when new articles cite this article. Sign up in the service box at the top right corner of the online article.

Notes

To request permissions go to:

http://group.bmj.com/group/rights-licensing/permissions

To order reprints go to:

http://journals.bmj.com/cgi/reprintform

To subscribe to BMJ go to:

http://journals.bmj.com/cgi/ep 


\title{
Cause-specific mortality of Dutch chlorophenoxy herbicide manufacturing workers
}

\author{
D Boers, ${ }^{1}$ L Portengen, ${ }^{1}$ H Bas Bueno-de-Mesquita, ${ }^{2}$ D Heederik, ${ }^{1}$ R Vermeulen ${ }^{1}$
}

${ }^{1}$ Institute for Risk Assessment Sciences (IRAS), Utrecht University, Utrecht, the Netherlands; ${ }^{2}$ The National Institute for Public Health and Environmental Protection (RIVM), Bilthoven, the Netherlands

\section{Correspondence to:}

Daisy Boers, Utrecht University, Institute for Risk Assessment Sciences, Department of Environmental Epidemiology, PO Box 80178, 3508 TD, Utrecht, the Netherlands; d.boers@uu.nl

Accepted 1 August 2009 Published Online First

6 September 2009

\section{ABSTRACT}

Objective: A retrospective cohort study was conducted in two chlorophenoxy herbicide manufacturing factories, producing mainly 2,4,5-trichlorophenoxyacetic acid (factory A) and 4-chloro-2-methylphenoxyacetic acid, 4chloro-2-methylphenoxy propanoic acid and 2,4-dichlorophenoxyacetic acid (factory B). Previously, we have shown elevated risks for mortality and cancer mortality in this cohort. The purpose of the current, third follow-up, is to provide an updated assessment of cause-specific mortality for both factories.

Methods: The study population was defined as all persons working in one of the two factories during 1955-1985 for factory A, or during 1965-1986 for factory B. Analyses were performed using Cox proportional hazard models, using attained age as the timescale. Exposure to phenoxy herbicides and dioxins was expected to be different for factory $A$ and factory $B$ and the factories were therefore analysed separately.

Results: Previously reported increased risks for respiratory cancer, non-Hodgkin's lymphoma and ischaemic heart disease in factory A could not be confirmed in the present analysis. However, increased risks were observed for all cancers in both factory A (hazard ratio (HR) 1.31; 95\% Cl 0.86 to 2.01) and factory B (HR 1.54; 95\% Cl 1.00 to 2.37). Increased risks for urinary cancers (HR 4.2; $95 \%$ $\mathrm{Cl} 0.99$ to 17.89) and genital cancers (HR 2.93; 95\% Cl 0.61 to 14.15$)$ were observed in factory $A$, consistent with earlier reported results in this population. More detailed analyses showed that this increased risk for urinary and genital cancers in exposed workers was not due to selection of healthy controls and could not be attributed to specific products or departments.

Conclusion: The results of this study showed only slight increases in cancer mortality risk. The increased risk for urinary cancers is noteworthy, but could not be linked to a specific exposure and needs to be confirmed in similar cohorts.

Chlorophenoxy herbicides have been widely used throughout the world as herbicides to control weeds since the early 1940s. 4-Chloro-2-methylphenoxyacetic acid (MCPA) and 2,4-dichlorophenoxyacetic acid $(2,4-\mathrm{D})$ were used in the control of broadleaf weeds in cereal crops, sugar cane, lawns and turfs, pastures and non-cropland, while 2,4,5trichlorophenoxyacetic acid $(2,4,5-\mathrm{T})$ was used for the control of woody and herbaceous weeds. Mixtures of 2,4-D and 2,4,5-T were also deployed during the Vietnam War as Agent Orange or Agent Purple for defoliation and crop destruction. ${ }^{12}$ Production of some of these herbicides (2,4,5-T and its derivates) has been banned in most countries since the late 1970s, because of the potential contamination with polychlorinated

\section{What this paper adds}

- Occupational exposure to chlorophenoxy herbicides and contaminants such as dioxins has been associated with increased risk of all cancers, respiratory cancers, soft-tissue sarcoma and non-Hodgkin's lymphoma (NHL) in some, but not all, studies.

- In this third follow-up of an occupational cohort, previously reported increased risks for respiratory cancers, $\mathrm{NHL}$, and ischaemic heart disease could not be confirmed.

- However, an increased risk for mortality of urinary and genital cancers was found in a factory that produced $2,4,5$ trichlorophenoxyacetic acid, 2,5-dichlorophenol, and 2,4,5-trichlorophenol and where some workers were exposed to high levels of 2,3,7,8tetrachlorodibenzo-p-dioxin during an industrial accident.

dibenzo-p-dioxins (PCDDs or also referred to as dioxins), including the most toxic congener 2,3,7,8tetrachlorodibenzo-p-dioxin (TCDD). ${ }^{3}$

Several studies among herbicide manufacturing workers have reported associations between exposure to chlorophenoxy herbicides, chlorophenols and contaminants, most prominently dioxins, with increased risks of all cancers, ${ }^{4-8}$ soft tissue sarcoma (STS), ${ }^{9-13}$ non-Hodgkin's lymphoma $(\mathrm{NHL})^{4} 6712$ and/or respiratory cancer, ${ }^{46}$ whereas other studies did not. ${ }^{14-16}$

In 1997 the International Agency for Research on Cancer (IARC) classified 2,3,7,8-TCDD as a group 1 carcinogen, ${ }^{17}$ based on sufficient evidence in animal experiments; evidence from mechanistic studies showing similar mode of action for TCDD in animals and humans, and studies in humans, based on results from four studies on highly exposed industrial cohorts (including the Dutch cohort that we report on) and the Seveso cohort.

The Dutch cohort consisted of two factories (referred to as factory A and factory B) producing and formulating chlorophenoxy herbicides. In factory $\mathrm{A}$ the main product was $2,4,5-\mathrm{T}$, while in factory $B$ the main products were MCPA, 4-chloro2-methylphenoxy propanoic acid (MCPP) and in smaller amounts 2,4-D. The first follow-up covered the years 1955-1985 for factory A and 1965-1986 for factory B, and revealed an increased risk for allcause mortality. The second follow-up extended the follow-up period until 1991 and included only factory A (due to a small number of deaths in factory B). This study confirmed results from the 
first follow-up and in addition reported increased risks of all cancers, respiratory cancers, NHL and ischaemic heart disease. For other (rare) types of cancer the number of cases was too small to draw any clear conclusions.

The purpose of the current (third) follow-up is to provide an updated analysis of (cancer) mortality in both factory A and factory $\mathrm{B}$, with an additional 15 years of follow-up added through to the end of 2006.

\section{MATERIALS AND METHODS}

\section{The companies}

The cohort includes workers from two factories, involved in the production and formulation of chlorophenoxy herbicides. In factory A, the main product 2,4,5-T was produced from 1953 until 1969 for approximately 200 tons per year. Formulation of 2,4,5-T continued until 1976 (see table 1). Other pesticides produced in factory A were, for example, 2,5-dichlorophenol (2,5-DCP), 2,4,5-trichlorophenol (2,4,5-TCP), lindane and tetradifon. These were produced in different production units to avoid contamination. In March 1963, an uncontrolled reaction occurred in an autoclave where 2,4,5-TCP was synthesised. After an explosion, the contents of the autoclave were released in the factory hall, which included dioxins such as TCDD. ${ }^{18}$

In factory B, 2,4-D was produced for approximately 140 tons per year from 1966 until 1972. In later years the factory produced mostly MCPA and MCPP.

During production of $2,4-\mathrm{D}$, dioxins (predominantly dioxins with 2-3 chlorine atoms) and dioxin-like compounds (like polychlorinated dibenzofurans (PCDFs) and polychlorinated biphenyls (PCBs)) may be formed as possible contaminants, while during production of 2,4,5-T and 2,4,5-TCP contamination with TCDD may also occur. However, since there is no information on the actual level or type of contaminants produced, in factory A and factory B exposure can only be defined rather broadly as meaning exposure to chlorophenoxy herbicides and/or contaminants, most importantly dioxins.

\section{Study population}

The start of follow-up for each factory was determined by completeness of personnel records and availability of mortality information.

For factory A, all workers ever employed between 1955 and 1985 ( $n=1167)$ were enrolled in the study, including 85 contract workers who were hired to help clean up after the accident in 1963. Eleven subjects (five contract workers) were excluded because of either unknown date of birth $(n=10)$ or unknown end of follow-up $(n=1)$. One (deceased) individual who was included as a male worker in earlier analyses appeared to be female upon linking to the death registry. ${ }^{18}$ In factory $\mathrm{B}$ all workers ever employed between 1965 and $1986(n=1143)$ entered the cohort. One individual was excluded from the analysis because of unknown end of follow-up. As in factory A, one (deceased) individual who was included as a male in earlier analyses appeared to be a female upon linking to the death registry. Since there were only few female workers in the cohort $(n=192)$, these were excluded from further analysis. Information on vital status was obtained from municipal records (GBA). Vital status of cohort members was updated until 31 December 2006.

The final study population consisted of 2106 male workers, contributing a total of 65087 person-years. Of these, 1430 male workers were still alive at the end of follow-up, 567 workers had died, 16 workers were lost to follow-up, and 93 workers had emigrated.
Cause-specific mortality for deceased workers was obtained by linkage to death certificates at Statistics Netherlands (CBS). Linkage was unsuccessful for 12 deceased workers and these were therefore excluded from further analysis.

\section{Exposure assessment}

Workers were classified as exposed to chlorophenoxy herbicides, chlorophenols and/or contaminants if: (1) they were employed in any of the following departments: "synthesis", "finishing", "formulation", "packing", "maintenance/repair", "laboratory", "chemical effluent/waste", "cleaning", "shipping/transport", or "plant supervision"; (2) they were exposed as a result of the accident in 1963 (factory A only); or (3) they were exposed by proximity (defined as not working in any department listed above, but entering these departments at least once a week on a regular basis). All other workers (office or manual workers) were classified as non-exposed to chlorophenoxy herbicides and contaminants. For the exposed, a distinction was made of whether or not they had ever worked in main production departments (synthesis, finishing, formulation, packing, chemical/effluent waste or other production departments). For 34 workers no information was available to define their exposure status, and these were therefore excluded from further analysis.

Within the group of exposed workers, workers who had been exposed as a result of the accident in 1963 and workers in any of the main production departments were assumed to be higher exposed than other exposed subjects. Workers in main production who had also been involved in cleaning up after the accident were classified as exposed due to the accident. We did not use the earlier published predictive model for dioxin exposure in this population, ${ }^{6}{ }^{19}$ since this was available only for factory A and was based on only a small number of blood samples. Results from using these model-based dioxin exposure estimates for factory A on data from the current follow-up are presented in the appendix for all cancers and lung cancer.

Back-extrapolated ( $t_{1 / 2}=7.1$ years) mean levels of TCDD as measured in 1993 support our a priori ranking of the above exposure groups. Highest mean TCDD levels were found among workers involved in the 1963 accident (1841.8 ppt) and working in main production (608.2 ppt), while levels in non-exposed workers were much lower (7.6 ppt). ${ }^{19}$

\section{Statistical methods}

Exposure-response relations were analysed by means of Cox proportional hazard models, using attained age as the timescale. Hazard ratios (HRs) were calculated for exposed workers versus non-exposed workers with corresponding 95\% confidence intervals. Because of the very different exposures (different chlorophenoxy herbicides, as well as by-products, and contaminants), analyses for factory $\mathrm{A}$ and $\mathrm{B}$ were performed separately. Deaths occurring within 1 year after first exposure were excluded from analysis, since these were considered to be unrelated to the exposure of interest. End of follow-up occurred within 1 year after first exposure for three subjects from factory $A$ and these were therefore excluded from further analysis.

Stratified analyses were performed by a priori exposure groups defined above, that is: (1) involved in the clean-up after the accident in 1963 (factory A only); (2) working in a main production department (factory A and factory B); and (3) working in other departments or being exposed as a result of frequently entering a production department (factory A and factory B). 
Table 1 Compounds synthesised and formulated in factory A and factory B, producing chlorophenoxy herbicides in the Netherlands

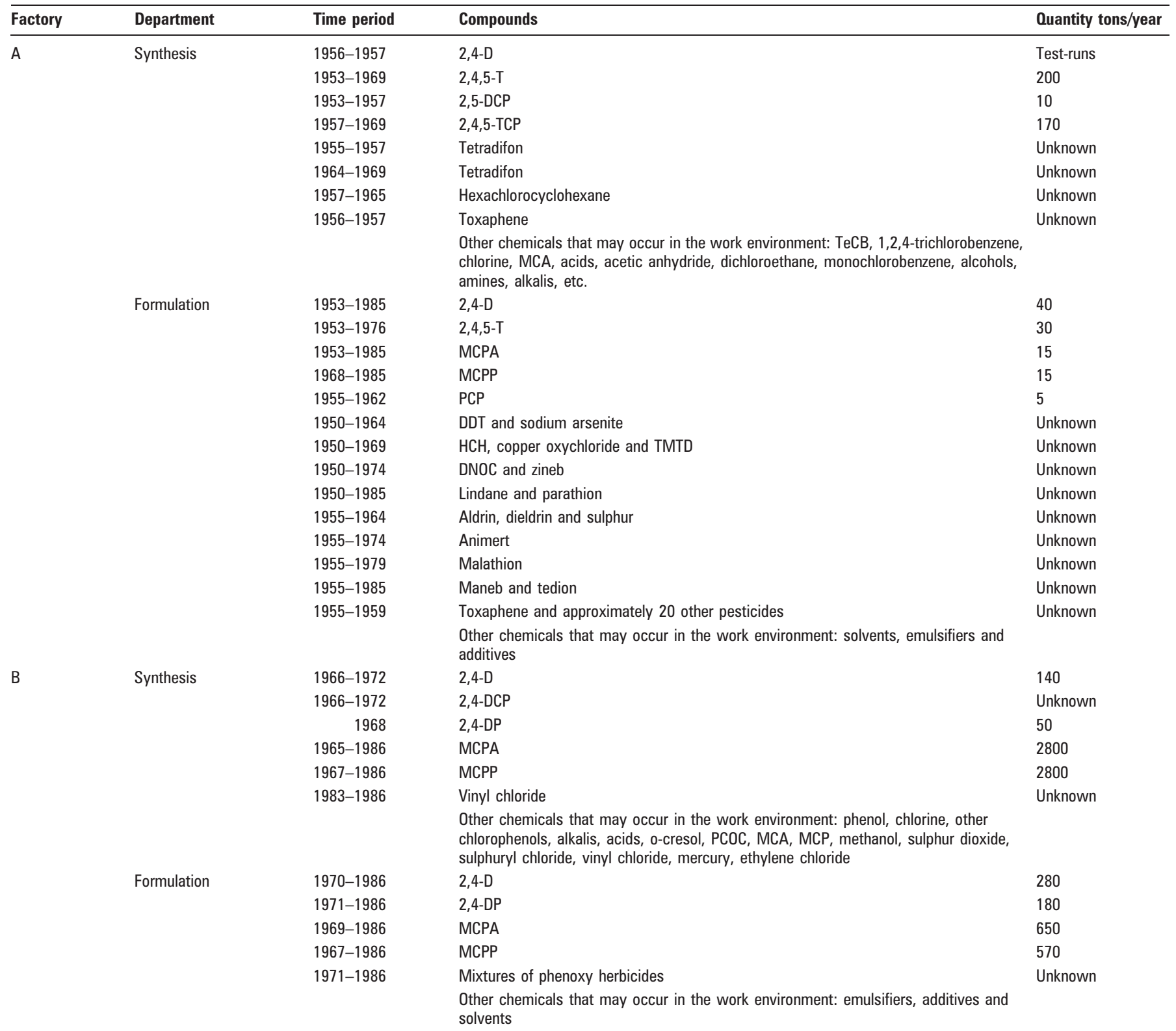

2,4-D, 2,4-dichlorophenoxy acetic acid; 2,4-DCP, 2,4-dichlorophenol; 2,5-DCP, 2,5 dichlorophenol; DDT, dichloro-diphenyl-trichloroethane; DNOC, dinitrocresol; 2,4-DP, 2,4dichlorophenoxy propanoic acid; $\mathrm{HCH}$, hexachlorocyclohexane; MCA, monochloro acetic acid; MCP, monochloropropanoic acid; MCPA, 4-chloro-2-methylphenoxy acetic acid; MCPP, 4-chloro-2-methylphenoxy propanoic acid; PCOC, p-chloro-0-cresol; PCP, pentachlorophenol; 2,4,5-T, 2,4,5-trichlorophenoxy acetic acid; 2,4,5-TCP, 2,4,5-trichlorophenol; TeCB, 1,2,4,5-tetrachlorobenzene; TMTD, tetramethyl-thiuram-disulphide.

To further investigate potential confounding of the exposureresponse relation between chlorophenoxy herbicides and (urinary) cancers by work-related co-exposures, a nested case-control study was performed in factory A using all cancer cases $(n=112)$ and three controls per case matched on age and employment period. Detailed information on the production departments where these workers had been employed was gathered from the original personnel files. The data were analysed using conditional logistic regression relating case status (either all cancers, lung cancer, or urinary cancers) to the production department where a subject had worked (eg in production of 2,4,5-T, lindane, dichlobenil, in the radioactive isotope laboratory, etc). Forty-seven (10\%) subjects had worked in multiple production departments and were assigned to the unit with the highest expected exposure to chlorophenoxy herbicides (eg, if a subject with multiple jobs ever worked in synthesis of 2,4,5-T, he was assumed to have been working in this department). Ranking was conducted prior to the casecontrol analysis.

All analyses were performed using the STATA software package V.9.0. ${ }^{20}$

\section{RESULTS}

Detailed information on the main chemical compounds that were produced in factory A and factory B is provided in table 1.

For factory A, a total of 539 male workers were classified as exposed and 482 as non-exposed. One hundred and thirty-nine workers (including 20 workers working in the clean-up after the accident) held jobs in main production departments. For factory $B$, a total of 411 male workers were classified as exposed and 626 
as non-exposed. One hundred and thirty-seven workers held jobs in main production departments. Exposed workers from factory A were on average employed at an earlier calendar period than non-exposed workers, and were slightly older at first employment (table 2).

In factory B no difference between year of first employment between exposed and non-exposed workers was observed. Year of first employment was therefore included in the exposureresponse models for factory A (using the median of 1965 as a cut point), but not for factory B. Hazard ratios for cause-specific mortality in exposed workers versus non-exposed workers are presented in table 3 for both factory A and factory B.

All cancer mortality was increased (HR 1.31; 95\% CI 0.86 to 2.01) for exposed workers in factory $A$, but the previously reported increased risks ${ }^{6}$ for NHL (HR 0.92; 95\% CI 0.19 to 4.47), respiratory cancer (HR 1.11; 95\% CI 0.49 to 2.52 ) and ischaemic heart disease (HR 1.15; 95\% CI 0.66 to 1.98) could not be confirmed. Increased risks were found for mortality from cancer of genital organs (prostate cancer; HR 2.93; 95\% CI 0.61 to 14.15 ) and urinary organs (bladder cancer and kidney cancer; HR 4.20; 95\% CI 0.99 to 17.89).

For factory B mortality was increased in exposed workers for respiratory cancer (HR $1.22 ; 95 \%$ CI 0.56 to 2.66 ), lymphatic and haematopoietic cancer (HR 1.52; 95\% CI 0.31 to 7.44 ) and ischaemic heart disease (HR 1.56; 95\% CI 0.79 to 3.11), but only the HR for all cancers (HR 1.54; 95\% CI 1.00 to 2.37) was borderline statistically significant. An increased risk for mortality from cancer of genital organs was also found in exposed workers from factory B (HR 3.28; 95\% CI 0.63 to 17.15). Unlike other studies that report increased risks for STS, we found only one death from STS in factory A (non-exposed worker) and none in factory B.

In factory A three a priori different exposure groups were distinguished: (1) workers exposed as a result of the accident in 1963 ("accident"); (2) workers occupied in main production departments ("main production"); and (3) workers who have been exposed as a result of frequently entering production departments ("occasionally exposed"). Results of the stratified analyses per exposure category, comparing each to the nonexposed referent workers, are presented in table 4.

Increased mortality risks from cancer were observed in workers exposed as a result of the accident (HR 1.56; 95\% CI 0.86 to 2.80 ), and in occasionally exposed workers (HR 1.46; $95 \%$ CI 0.90 to 2.35 ), but not in workers involved in main production (HR 0.85 ; $95 \%$ CI 0.44 to 1.66 ). Mortality from lung cancer was increased only in occasionally exposed workers (HR 1.45; $95 \%$ CI 0.58 to 3.63). Increased risks for urinary cancers were found in all exposure groups, but were especially high in workers that were involved in main production (HR 4.33; 95\% CI 0.95 to 19.65 ) and in workers occasionally exposed (HR 5.29; $95 \%$ CI 1.19 to 23.52 ). Furthermore, mortality from ischaemic heart disease was increased only in workers involved in the clean-up after the accident (HR 1.60; 95\% CI 0.72 to 3.55).

Effect estimates from logistic regression analysis of the nested case-control data using exposure to chlorophenoxy herbicides as the independent variable were very similar to those obtained with the Cox proportional hazards model, and were only slightly increased when department was included in the model (not shown). Elevated risks for urinary cancers were observed in several production departments (eg, lindane production, dichlobenil production, tetradifon, or 2,4,5-T/chlorophenoxy herbicide production) and thus appeared not to be restricted to a particular production process. Risk of mortality from all cancers (odds ratio $(O R) 17.5 ; p=0.00$ ) and lung cancer (OR 10.6; $\mathrm{p}=0.11$ ) appeared to be particularly high for workers employed in two production departments using radioactive isotopes (production and laboratory), but this could not be explored further.

In factory $\mathrm{B}$ only two exposure categories could be distinguished, that is, workers in main production departments

Table 2 Population characteristics for exposed and non-exposed male workers from factory A and factory B, the Netherlands, 1955-2006

\begin{tabular}{|c|c|c|c|c|c|c|c|c|}
\hline & \multicolumn{4}{|c|}{ Factory A } & \multicolumn{4}{|c|}{ Factory B } \\
\hline & \multicolumn{2}{|c|}{ Exposed } & \multicolumn{2}{|c|}{ Non-exposed } & \multicolumn{2}{|c|}{ Exposed } & \multicolumn{2}{|c|}{ Non-exposed } \\
\hline & No & $\%$ & No & $\%$ & No & $\%$ & No & $\%$ \\
\hline No. of workers & 539 & 52.8 & 482 & 47.2 & 411 & 39.6 & 626 & 60.4 \\
\hline Person-years at risk & 18811 & & 14749 & & 12946 & & 18581 & \\
\hline Mean (SD) age at entry* & 32 & & 29. & & 31. & & 30. & \\
\hline \multicolumn{9}{|l|}{ Vital status } \\
\hline Alive & 277 & 51.4 & 351 & 72.8 & 306 & 74.4 & 479 & 76.5 \\
\hline Deceased & 233 & 43.2 & 106 & 22.0 & 90 & 21.9 & 112 & 17.9 \\
\hline Lost to follow-up & 1 & 0.2 & 6 & 1.2 & 4 & 1.0 & 4 & 0.6 \\
\hline Emigrated & 28 & 5.2 & 19 & 3.9 & 11 & 2.7 & 31 & 5.0 \\
\hline \multicolumn{9}{|c|}{ Age at first employment (years) } \\
\hline$<25$ & 155 & 28.8 & 171 & 35.5 & 143 & 34.8 & 182 & 29.1 \\
\hline $25-34$ & 204 & 37.9 & 204 & 42.3 & 145 & 35.3 & 265 & 42.3 \\
\hline $35-44$ & 128 & 23.8 & 73 & 15.1 & 81 & 19.9 & 131 & 20.9 \\
\hline$>45$ & 52 & 9.6 & 34 & 7.1 & 42 & 10.3 & 48 & 7.7 \\
\hline \multicolumn{9}{|l|}{ Year of first employment } \\
\hline Before 1955 & 56 & 10.4 & 21 & 4.4 & - & - & 1 & 0.2 \\
\hline 1955-1964 & 302 & 56.0 & 100 & 20.8 & 68 & 16.6 & 46 & 7.4 \\
\hline 1965-1974 & 145 & 26.9 & 173 & 35.9 & 206 & 50.1 & 311 & 49.7 \\
\hline 1975 and later & 36 & 6.7 & 188 & 39.0 & 137 & 33.3 & 268 & 42.8 \\
\hline \multicolumn{9}{|c|}{ Duration of employment (years) ${ }^{*}$} \\
\hline $0-5$ & 302 & 56.1 & 309 & 64.4 & 103 & 25.1 & 296 & 47.4 \\
\hline $5+$ & 237 & 43.9 & 171 & 35.6 & 308 & 74.9 & 329 & 52.6 \\
\hline
\end{tabular}

${ }^{*}$ An additional three subjects have been excluded from analysis with duration of employment due to missing data on exit job. 
Table 3 Hazard ratios (HRs) by cause of death for exposed male workers compared with non-exposed male workers, the Netherlands, 1955-2006

\begin{tabular}{|c|c|c|c|c|}
\hline \multirow[b]{2}{*}{ Causes of death (ICD 10th revision) } & \multicolumn{2}{|l|}{ Factory $\mathrm{A}$} & \multicolumn{2}{|l|}{ Factory B } \\
\hline & $\begin{array}{l}\text { Exposed/non- } \\
\text { exposed }\end{array}$ & $\mathrm{HR}^{*} \dagger(95 \% \mathrm{Cl})$ & $\begin{array}{l}\text { Exposed/non- } \\
\text { exposed }\end{array}$ & $\mathrm{HR}^{*}(95 \% \mathrm{Cl})$ \\
\hline All causes $(A 00-Y 89)$ & $234 / 106$ & $1.16(0.91$ to 1.47$)$ & $90 / 112$ & $1.02(0.77$ to 1.34$)$ \\
\hline All cancers (COO-D48) & $81 / 31$ & 1.31 (0.86 to 2.01$)$ & $44 / 36$ & $1.54(1.00$ to 2.37$)$ \\
\hline Digestive cancers (C15-C26) & $18 / 7$ & 1.23 (0.50 to 2.99 ) & $12 / 12$ & 1.25 (0.58 to 2.71$)$ \\
\hline Stomach (C16) & $5 / 1$ & 2.23 (0.38 to 13.20$)$ & $4 / 4$ & 1.21 (0.31 to 4.65$)$ \\
\hline Trachea, bronchus and lung (C33-C34) & $20 / 7$ & 1.15 (0.48 to 2.77$)$ & $12 / 12$ & $1.22(0.56$ to 2.66$)$ \\
\hline Malignant melanoma of skin (C43-C44) & $3 / 2$ & $0.72(0.07$ to 7.03$)$ & $1 / 2$ & $1.53(0.10$ to 23.84$)$ \\
\hline Genital and urinary cancers (C51-C68) & $23 / 4$ & $3.78(1.24$ to 11.52$)$ & $6 / 4$ & $1.82(0.51$ to 6.48$)$ \\
\hline Genital cancers (C51-C63) & $6 / 2$ & $2.93(0.61$ to 14.15$)$ & $5 / 2$ & $3.28(0.63$ to 17.15$)$ \\
\hline Prostate (C61) & $6 / 2$ & $2.93(0.61$ to 14.15$)$ & $4 / 2$ & $2.68(0.48$ to 14.85$)$ \\
\hline Non-Hodgkin's lymphoma (C82-C83, C85) & $4 / 3$ & $0.92(0.19$ to 4.47$)$ & $1 / 0$ & $\operatorname{lnf:}$ \\
\hline Leukaemia (C91-C95) & $2 / 3$ & $0.28(0.03$ to 2.61$)$ & $2 / 2$ & $1.53(0.22$ to 10.82$)$ \\
\hline Benign and unspecified cancers (D00-D48) & $1 / 2$ & $0.17(0.02$ to 1.84$)$ & $2 / 2$ & $1.28(0.19$ to 8.46$)$ \\
\hline Disease of endocrine system and blood (D50-E89) & $6 / 4$ & $1.05(0.26$ to 4.15$)$ & $0 / 1$ & $\sim 0 \S$ \\
\hline Mental disorders (F00-F99) & $3 / 1$ & $1.30(0.12$ to 14.68$)$ & $1 / 1$ & $1.16(0.10$ to 13.54$)$ \\
\hline Disease of nervous system and sense organs (G00-H95) & $8 / 2$ & $2.15(0.35$ to 13.20$)$ & $1 / 2$ & 0.65 (0.06 to 7.54$)$ \\
\hline Diseases of circulatory system (100-199) & $77 / 37$ & 1.07 (0.70 to 1.62$)$ & $31 / 37$ & $1.06(0.66$ to 1.70$)$ \\
\hline Ischaemic heart diseases (120-125) & $43 / 18$ & $1.15(0.66$ to 1.98$)$ & $18 / 15$ & $1.56(0.79$ to 3.11$)$ \\
\hline Other heart diseases (I30-151) & $7 / 7$ & $0.55(0.19$ to 1.60$)$ & $4 / 9$ & $0.57(0.17$ to 1.86$)$ \\
\hline Cerebrovascular diseases (I60-I67) & $17 / 7$ & $1.23(0.42$ to 3.56$)$ & $7 / 8$ & $1.04(0.39$ to 2.80$)$ \\
\hline Diseases of respiratory system (J00-J98) & $19 / 12$ & $1.00(0.43$ to 2.29$)$ & $6 / 15$ & $0.46(0.18$ to 1.15$)$ \\
\hline Digestive system (K00-K92) & $6 / 6$ & $0.60(0.18$ to 2.01$)$ & $0 / 4$ & $\sim 0 \S$ \\
\hline
\end{tabular}

\footnotetext{
*HR adjusted for age.

†HRs for factory A were adjusted for year of first employment.

$\$ 95 \%$ confidence interval.

$\S$ Estimated HR is approximately zero.

-Estimated HR is infinitively large.
}

and workers who were only occasionally exposed (table 5). Mortality from all cancers was increased in both groups (HR 1.54 and HR 1.50, respectively), although not statistically significant. An increased risk of mortality from respiratory cancer (HR 2.14; 95\% CI 0.77 to 5.98) and urinary cancer (HR 2.56; $95 \%$ CI 0.24 to 27.10) was found for workers involved in main production. Mortality from genital organs cancer (HR 2.67 and 3.03) and ischaemic heart disease (HR 1.67 and 1.53) was increased for workers in both exposure categories.

HRs for selected causes of death according to duration of employment are presented in table AII (see appendix). Although the rather imprecise estimates complicate interpretation of these results, there appears to be no increased risk for exposed workers who have been employed for a longer time period.

\section{DISCUSSION AND CONCLUSION}

In this retrospective cohort study among 2.058 occupationally exposed male workers, risks for mortality from all cancers were only slightly increased in workers exposed to chlorophenoxy herbicides, chlorophenols and contaminants (dioxins and dioxin-like compounds) compared with non-exposed workers. However, cancer mortality from urinary and genital organs appeared to be higher in exposed workers in factory A, which is consistent with earlier findings in this cohort. ${ }^{6}$ An increased risk for genital organs cancer was also found in factory B.

This third follow-up adds approximately 15 years of followup to the previous analysis of this cohort and also includes factory B, which was previously excluded because of the small number of deaths that had occurred. We were especially interested in mortality from all cancers, respiratory cancers, and lymphatic and haematopoietic cancers, including NHL, as increased risks for these outcomes have been reported previously in this cohort as well as in a number of other studies. ${ }^{34} 611121621$

Increased risks for all cancer mortality (relative risk (RR) 4.1; 95\% CI 1.8 to 9.0 ), respiratory cancer (RR 7.5; 95\% CI 1.0 to 56.1), NHL (RR 1.7; 95\% CI 0.2-16.5), and ischaemic heart disease (RR 1.8; 95\% CI 0.9 to 3.6) that were reported previously by Hooiveld et a ${ }^{6}$ for factory A could not be confirmed in the present analysis. This could not be attributed to the different statistical models that were used as, for example, the estimated effect of exposure on lung cancer mortality using the Cox regression model based on data from the second follow-up (HR 6.6; $95 \%$ CI 0.9 to 51) was very similar to the reported RR from the Poisson regression model that was used (RR 6.5; 95\% CI 0.9 to 49). In addition, standard mortality ratios (SMRs) for total cancers (SMR 0.9; 95\% CI 0.7 to 1.1) and lung cancer mortality 
Table 4 Hazard ratios (HRs) for cause of death per exposure category for exposed male workers compared with non-exposed male workers in factory A, 1955-2006

\begin{tabular}{|c|c|c|c|c|c|c|}
\hline \multirow[b]{3}{*}{ Causes of death (ICD 10th revision) } & \multicolumn{6}{|l|}{ Factory $\mathrm{A}$} \\
\hline & \multicolumn{2}{|c|}{ Accident $1963(n=139)$} & \multicolumn{2}{|c|}{ Main production $(n=121)$} & \multicolumn{2}{|c|}{ Occasionally exposed $(n=286)$} \\
\hline & $\begin{array}{l}\text { Exposed/non- } \\
\text { exposed }\end{array}$ & $\mathrm{HR}^{*}(95 \% \mathrm{Cl})$ & $\begin{array}{l}\text { Exposed/non- } \\
\text { exposed }\end{array}$ & $\mathrm{HR}^{*}(95 \% \mathrm{Cl})$ & $\begin{array}{l}\text { Exposed/non- } \\
\text { exposed }\end{array}$ & $\mathrm{HR}^{*}(95 \% \mathrm{Cl})$ \\
\hline All causes (A00-Y89) & $76 / 106$ & $1.18(0.84$ to 1.65$)$ & $50 / 106$ & $1.04(0.73$ to 1.47$)$ & $108 / 106$ & $1.19(0.90$ to 1.56$)$ \\
\hline All cancers (C00-D48) & $30 / 31$ & $1.56(0.86$ to 2.80$)$ & $12 / 31$ & 0.85 (0.44 to 1.66$)$ & $39 / 31$ & $1.46(0.90$ to 2.35$)$ \\
\hline Digestive cancers (C15-C26) & $7 / 7$ & $1.50(0.43$ to 5.24$)$ & $2 / 7$ & 0.60 (0.12 to 2.98$)$ & $9 / 7$ & $1.44(0.54$ to 3.85$)$ \\
\hline Genital cancers (C51-C63) & $4 / 2$ & $\operatorname{lnf}:$ & $0 / 2$ & $\sim 0 \dagger$ & $2 / 2$ & $2.21(0.39$ to 12.45$)$ \\
\hline Prostate (C61) & $4 / 2$ & $\operatorname{lnf}:$ & $0 / 2$ & $\sim 0 \dagger$ & $2 / 2$ & $2.21(0.39$ to 12.45$)$ \\
\hline Urinary cancers (C64-C68) & $3 / 2$ & $3.37(0.37$ to 31.11$)$ & $4 / 2$ & $4.33(0.95$ to 19.65$)$ & $10 / 2$ & 5.29 (1.19 to 23.52$)$ \\
\hline Bladder (C67) & $2 / 2$ & $2.37(0.21$ to 26.08$)$ & $3 / 2$ & 3.31 (0.68 to 16.09$)$ & $4 / 2$ & $2.17(0.40$ to 11.63$)$ \\
\hline Kidney (C68) & $1 / 0$ & $\operatorname{lnf:}$ & $1 / 0$ & $\operatorname{lnf}:$ & $6 / 0$ & $\operatorname{lnf}:$ \\
\hline $\begin{array}{l}\text { Lymphatic and haematopoietic cancers } \\
\text { (C81-C96) }\end{array}$ & $3 / 7$ & $0.63(0.14$ to 2.81$)$ & $3 / 7$ & 0.98 (0.23 to 4.19 ) & $5 / 7$ & 0.84 (0.25 to 2.85$)$ \\
\hline Cerebrovascular disease (160-167) & $2 / 7$ & $0.27(0.05$ to 1.36$)$ & $5 / 7$ & $1.30(0.36$ to 4.70$)$ & $10 / 7$ & 1.50 (0.53 to 4.28$)$ \\
\hline Accidents, poisoning and violence ( $\mathrm{S} 00-\mathrm{YO}$ ) & $5 / 5$ & 4.33 (0.51 to 36.72 ) & $7 / 5$ & $3.91(1.52$ to 10.05$)$ & $2 / 5$ & 0.58 (0.13 to 2.52$)$ \\
\hline
\end{tabular}

${ }^{*} \mathrm{HR}$ adjusted for age and year of first employment.

$\dagger$ Estimated HR is approximately zero.

Estimated HR is infinitely large.

ICD, International Classification of Diseases.

(SMR 0.6; 95\% CI 0.4 to 0.8) in exposed workers were considerably lower than those reported in that paper as well (total cancers: SMR 1.5; 95\% CI 1.1 to 1.9 and lung cancer: SMR $1.0 ; 95 \%$ CI 0.6 to 1.7 ) suggesting that the difference is due to lower cancer mortality in exposed workers during the time period between the second and third follow-up. These discrepancies may be explained by the imprecision of both the earlier and current estimates, but could also indicate that we have moved beyond the aetiological time window, that competing risk factors have become more significant, or that the pool of susceptible subjects has been exhausted. The aetiological time window argument could be envisioned for chlorophenoxy herbicides that have a relatively short biological half-life of only hours or a few days, but it would be unlikely to play an important role for contaminants such as TCDD that have an estimated half-life of approximately 7.1 years. ${ }^{19}$

Associations between exposure to chlorophenoxy herbicides and contaminants and mortality from urinary cancers, such as bladder and kidney cancer, have been reported before in some studies $^{3422-26}$ although this has not been a consistent finding. ${ }^{14}{ }^{14} 21$ The strongly increased risk of mortality from urinary cancers that we report for exposed workers in factory A, although still based on a small number of cases, is therefore somewhat unexpected. Stratified analysis of cause-specific mortality for workers exposed as a result of the industrial accident in 1963 (involved in the clean-up after the accident), workers occupied in main production departments, and workers occasionally entering production departments showed that an

Table 5 Hazard ratios (HRs) for cause of death per exposure category for exposed male workers compared with non-exposed male workers in factory B, 1965-2006

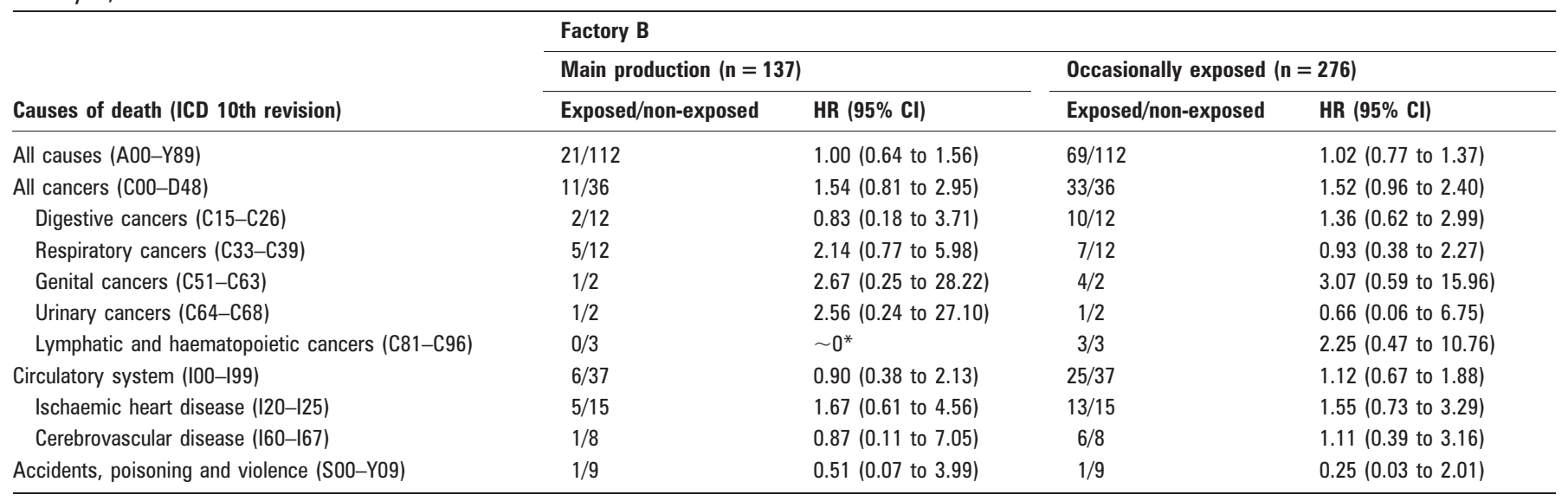

*Estimated HR is approximately zero.

ICD, International Classification of Diseases. 
increased risk of urinary cancer mortality was present in both workers in main production and in occasionally exposed workers. To ensure that these results were not due to lowerthan-expected mortality in our referent group of non-exposed workers, we calculated SMRs for both exposed and non-exposed workers, using mortality rates in the general Dutch population as a reference. Increased SMRs were found for both bladder cancer (SMR 3.72 (observed/expected; O/E 9/2.42)) and kidney cancer (SMR 3.69 (O/E 8/2.17) in exposed workers, while the SMR for bladder cancer in non-exposed workers was approximately 1 (SMR 1.61 (O/E 2/1.24)). No cases of kidney cancer were observed in unexposed workers (1.2 cases expected, SMR $=0$ ). However, due to the absence of a clear difference in urinary cancer mortality between occasionally exposed workers and workers employed in the main production departments, we considered the possibility that the increased risk might be due to confounding by other work-related exposures in factory A (eg lindane or tetradifon). However, more detailed investigation using a nested case-control design showed that the increased risk for urinary cancer mortality was not restricted to a single production department, but was present in most pesticideproducing units. This suggests that the risk may not be due to chlorophenoxy herbicide exposure per se. Also, we cannot rule out the possibility that our findings are due to chance, given the small number of cases on which these specific analyses are based.

In factory B, where mainly MCPP, MCPA and 2,4-D were produced, increased risks were found for mortality from all cancers, genital cancers and ischaemic heart disease. Evidence on a possible association between these substances and cancer risk remains controversial, with some studies reporting an increased risk for NHL and STS, ${ }^{11}{ }^{27}$ while others do not. ${ }^{14}{ }^{28}$ Because of the different chlorophenoxy herbicides that were produced and the potentially very different exposures, analyses were performed separately for factory A and factory B.

Only limited information was available on potential confounding factors. However, analyses using an internal and external control group were consistent; limiting the scope for confounding as an explanation for the observed risks. No information on smoking habits was available, but risk for lung cancer was very similar for exposed and unexposed workers in both factories, indicating that differences in smoking habits is unlikely to be a major confounder.

This Dutch cohort has several strengths. Accurate occupational job history information was obtained from company job records and validated. Workers were classified as exposed if they had been employed in departments where exposure to chlorophenoxy herbicides, or chlorophenols occurred. Nonexposed workers consisted of all workers employed in other factory halls located on the same factory grounds, as long as they did not qualify for our definition of exposure to chlorophenoxy herbicides or chlorophenols. We were therefore able to use an internal control group with similar social economic status for comparison. Although SMRs based on national mortality rates may be more stable, they may also introduce bias through the healthy worker effect. A disadvantage may be that our referent group of non-exposed workers is probably exposed to a variety of other chemicals (other pesticides, vinylchloride or radioactive isotopes). ${ }^{18}$ Although cause-specific SMRs showed that mortality rates for nonexposed workers were similar to that in the general population, we cannot rule out that there might have been some misclassification of exposure among non-exposed workers and occasionally exposed workers. Therefore, further analysis should focus on quantitative measures of dioxin, and dioxinlike compounds in this population.

In conclusion the results of this third follow-up of a cohort comprised of workers exposed to chlorophenoxy herbicides, chlorophenols and contaminants, showed only a slightly increased risk for mortality from all cancers in factory A, and confirmed previously reported increased risks for mortality from urinary (and genital) cancers in this factory. In factory B risk of all cancers was slightly increased in exposed workers also, as were risks of genital cancer and ischaemic heart disease. However, the number of cancer cases for any specific site remains small and it is therefore difficult to rule out chance or confounding as a possible explanation for these findings, even with approximately 15 years of additional follow-up. That we were unable to confirm some of the earlier findings, most notably the strongly increased risks for all cancer mortality and respiratory cancer, is cause for some concern as the IARC evaluation of chlorophenoxy herbicides carcinogenicity was partly based on this cohort. Note, however that the IARC evaluation was based on all cancer mortality rather than causespecific cancer mortality. A recent review of the epidemiological and mechanistic evidence concluded that the new evidence generally supports the 1997 IARC classification ${ }^{17}$; this seems to be true mostly for the mechanistic (animal) studies, while much of the epidemiological evidence is rather mixed especially for cause-specific cancer mortality.

Acknowledgements: The Central Bureau of Statistics (CBS) provided causes of death.

Competing interests: None.

Provenance and peer review: Not commissioned; externally peer reviewed.

\section{REFERENCES}

1. IARC. IARC monographs on the evaluation of the carcinogenic risk of chemicals to man, vol. 15: some fumigants, the herbicides 2,4-D and 2,4,5-T, chlorinated dibenzodioxins and miscellaneous industrial chemicals. Lyon: IARC, 1977.

2. IARC. IARC monographs on the evaluation of the carcinogenic risk of chemicals to humans, vol. 30. Miscellaneous pesticides. Lyon: IARC, 1983.

3. Kogevinas $\mathbf{M}$, Becher $\mathbf{H}$, Benn $\mathrm{T}$, et al. Cancer mortality in workers exposed to phenoxy herbicides, chlorophenols, and dioxins. An expanded and updated international cohort study. Am J Epidemiol 1997;145:1061-75.

4. Becher H, Flesch-Janys D, Kauppinen T, et al. Cancer mortality in German male workers exposed to phenoxy herbicides and dioxins. Cancer Causes Control 1996; 7:312-21

5. Zober A, Messerer P, Huber P. Thirty-four-year mortality follow-up of BASF employees exposed to 2,3,7,8-TCDD after the 1953 accident. Int Arch Occup Environ Health 1990;62:139-57.

6. Hooiveld M, Heederik DJ, Kogevinas M, et al. Second follow-up of a Dutch cohort occupationally exposed to phenoxy herbicides, chlorophenols, and contaminants. Am J Epidemiol 1998;147:891-901.

7. Dich J, Hoar-Zahm S, Hanberg A, et al. Pesticides and cancer. Cancer Causes Control 1997;8:420-43.

8. Flesch-Janys D, Berger J, Gurn P, et al. Exposure to polychlorinated dioxins and furans (PCDD/F) and mortality in a cohort of workers from a herbicideproducing plant in Hamburg, Federal Republic of Germany. Am J Epidemiol 1995;142:1165-75.

9. Pearce N, McLean D. Agricultural exposures and non-Hodgkin's lymphoma Scan J Work Environ Health 2005;31 (Suppl 1):18-25.

10. Kogevinas $\mathbf{M}$, Becher $\mathrm{H}$, Benn $\mathrm{T}$, et al. Cancer mortality in workers exposed to phenoxy herbicides, chlorophenols, and dioxins. Am J Epidemiol 1997;145:1061-75

11. Lynge E. Cancer in phenoxy herbicide manufacturing workers in Denmark, 194787-an update. Cancer Causes Control 1993;4:261-72.

12. Bodner KM, Collins JJ, Bloemen LJ, et al. Cancer risk for chemical workers exposed to 2,3,7,8-tetrachlorodibenzo-p-dioxin. Occup Environ Med 2003;60:672-5.

13. Kogevinas M, Kauppinen T, Winkelmann R, et al. Soft tissue sarcoma and nonHodgkin's lymphoma in workers exposed to phenoxy herbicides, chlorophenols, and dioxins: two nested case-control studies. Epidemiology 1995;6:396-402.

14. Coggon D, Pannett B, Winter PD, et al. Mortality of workers exposed to 2 methyl-4 chlorophenoxyacetic acid. Scand J Work Environ Health 1986;12:448-54.

15. Zack JA, Suskind RR. The mortality experience of workers exposed to tetrachlorodibenzodioxin in a trichlorophenol process accident. J Occup Med 1980;22:11-4. 
16. Fingerhut MA, Halperin WE, Marlow DA, et al. Cancer mortality in workers exposed to 2,3,7,8-tetrachlorodibenzo-p-dioxin. N Engl J Med 1991;324:212-8.

17. Steenland K, Bertazzi PA, Baccarelli A, et al. Dioxin revisited developments since the 1997 IARC classification of dioxin as a human carcinogen. Environ Health Perspect 2004;12:1265-8

18. Bueno de Mesquita HB, Doornbos G, Van der Kuip DA, et al. Occupational exposure to phenoxy herbicides and chlorophenols and cancer mortality in The Netherlands. Am J Ind Med 1993;23:289-300.

19. Heederik D, Hooiveld M, Bueno-de-Mesquita HB. Modelling of 2,3,7,8tetrachlorodibenzo-p-dioxin levels in a cohort of workers with exposure to phenoxy herbicides and chlorophenols. Chemosphere 1998;37:1743-54.

20. StataCorp. Stata Statistical Software: Release 10. Collage Station: StataCorp LP, 2007.

21. Ott MG, Zober A. Cause specific mortality and cancer incidence among employees exposed to 2,3,7,8-TCDD after a 1953 reactor accident. Occup Environ Med 1996;53:606-12.

22. Ia Vecchia C, Negri E, D'Avanzo B, et al. Occupation and the risk of bladder cancer. Int J Epidemiol 1990;19:264-8.

23. Demers PA, Davies HW, Friesen MC, et al. Cancer and occupational exposure to pentachlorophenol and tetrachlorophenol (Canada). Cancer Causes Control 2006:17:749-58.

24. Hu J, Mao Y, White K. Renal cell carcinoma and occupational exposure to chemicals in Canada. Occup Med (Lond) 2002;52:157-64.

25. Ramlow JM, Spadacene NW, Hoag SR, et al. Mortality in a cohort of pentachlorophenol manufacturing workers, 1940-1989. Am J Ind Med 1996:30:180-94.

26. Collins JJ, Strauss ME, Levinskas GJ, et al. The mortality experience of workers exposed to 2,3,7,8-tetrachlorodibenzo-p-dioxin in a trichlorophenol process accident. Epidemiology 1993:4:7-13.

27. Lynge E. Cancer incidence in Danish phenoxy herbicide workers, 1947-1993. Environ Health Perspect 1998;106(Suppl 2):683-8.

28. Burns CJ, Beard KK, Cartmill JB. Mortality in chemical workers potentially exposed to 2,4-dichlorophenoxyacetic acid (2,4-D) 1945-94: an update. Occup Environ Med 2001;:58:24-30.

\section{APPENDIX}

Hazard ratios for all cancer and lung cancer mortality at the present (third) follow-up and 2,3,7,8-tetrachlorodibenzo-p-dioxin (TCDD) exposure as estimated by the predictive model from Hooiveld et $a l^{6}$ are presented in table Al. The predictive exposure model is based on back extrapolation of TCDD measurements in serum collected from a sample of exposed workers $(n=47)$ from factory $A$ in 1993. The low exposure (reference) category includes workers with highest (ever) TCDD levels below 7.1 ppt (lipid adjusted). Medium exposure was defined as maximal TCDD levels between $7.1 \mathrm{ppt}$ and $124.1 \mathrm{ppt}$ and high exposure as maximal TCDD levels > $124.1 \mathrm{ppt}$.

Table Al Hazard ratios (HRs) for cancer mortality and estimated 2,3,7,8-tetrachlorodibenzo-p-dioxin exposure using the predictive model by Hooiveld et al ${ }^{6}$

\begin{tabular}{ll}
\hline Cause of death (ICD 10th revision) & HR $^{*}(\mathbf{9 5 \%} \mathbf{C l} \dagger)$ \\
\hline All cancers (C00-D48) & \\
$\quad$ Medium versus low & $1.2(0.73$ to 1.96$)$ \\
High versus low & $1.4(0.85$ to 2.26$)$ \\
Lung cancer (C33-C34) & \\
$\quad$ Medium versus low & $0.8(0.31$ to 2.33$)$ \\
High versus low & $1.6(0.6$ to 4.0$)$ \\
\hline
\end{tabular}

*HR adjusted for year of first employment.

$\uparrow 95 \%$ confidence interval.

ICD, International Classification of Diseases.

Hazard ratios for a few selected causes of death according to duration of employment $(\leqslant$ or $>5$ years) and factory are presented in table All. Estimates are rather imprecise and do therefore not allow strong conclusions, but there appear to be no large differences in risk between long- and short-term employed workers.

Table All Hazard ratios (HRs) for selected causes of death according to duration of employment, the Netherlands, 1955-2006

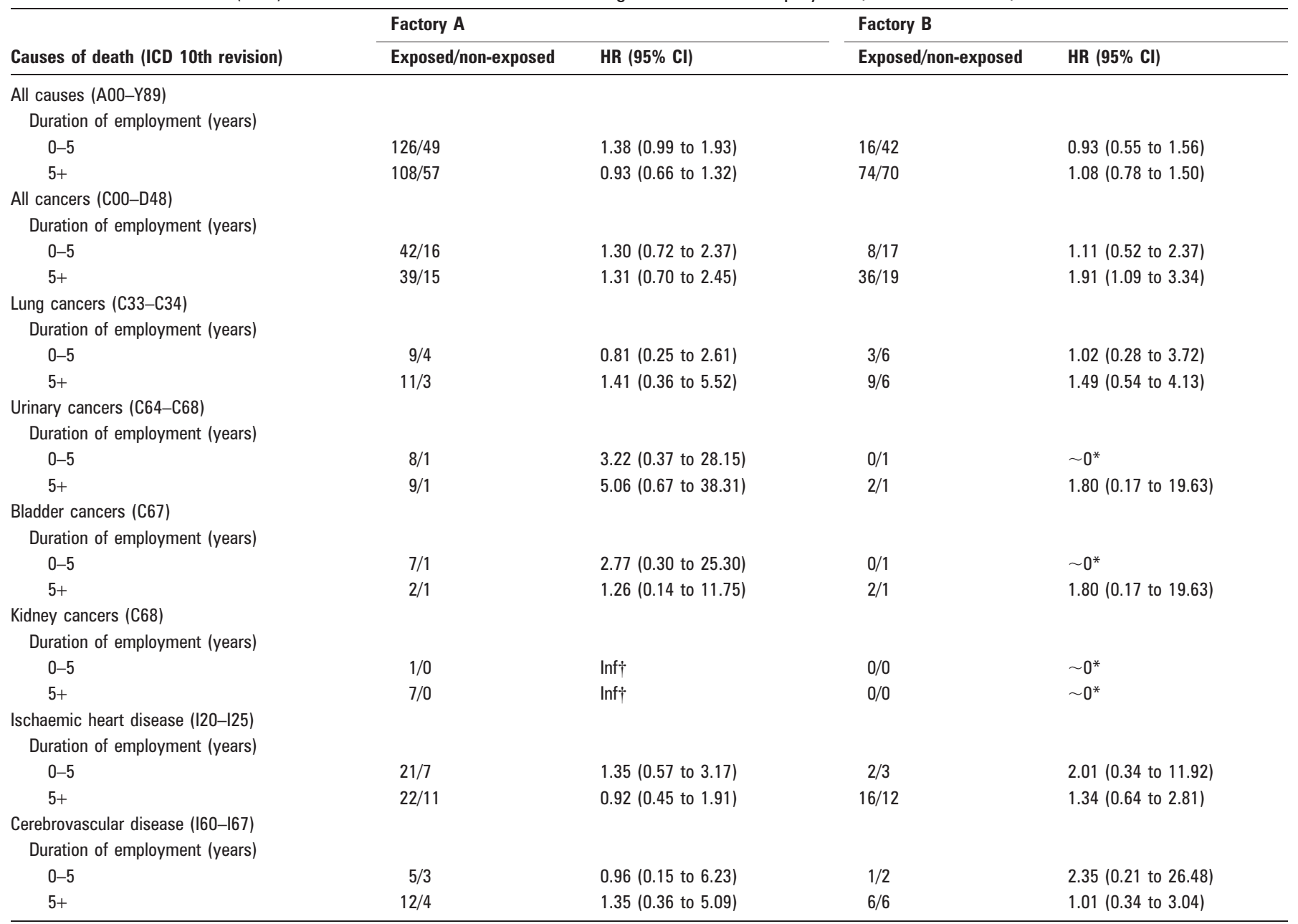

*Estimated HR is approximately zero.

$\dagger$ Estimated HR is infinitively large.

ICD, International Classification of Diseases. 